\title{
Porcine Cysticercosis Control in Western Kenya: The Interlink of Management Practices in Pig Farms and Meat Inspection Practice at Slaughter Slabs
}

\author{
Marie-Françoise Mwabonimana $\mathbb{D}^{1},{ }^{1,2}$ Charles Muleke Inyagwa, ${ }^{3}$ Bockline Omedo Bebe, \\ Eduard Kokan Shakala, ${ }^{1}$ and Anthony Macharia King'ori ${ }^{1}$ \\ ${ }^{1}$ Department of Animal Science, Faculty of Agriculture, Egerton University, P.O. Box 536-20115, Egerton, Kenya \\ ${ }^{2}$ College of Animal Sciences and Veterinary Medicine, University of Rwanda, P.O. Box 210, Musanze, Rwanda \\ ${ }^{3}$ Department of Veterinary Medicine, Faculty of Veterinary Medicine and Surgery, Egerton University, P.O. Box 536-20115, \\ Egerton, Kenya
}

Correspondence should be addressed to Marie-Françoise Mwabonimana; mdorcas2001@yahoo.fr

Received 2 March 2020; Revised 3 August 2020; Accepted 9 August 2020; Published 27 August 2020

Academic Editor: Francesca Mancianti

Copyright (c) 2020 Marie-Françoise Mwabonimana et al. This is an open access article distributed under the Creative Commons Attribution License, which permits unrestricted use, distribution, and reproduction in any medium, provided the original work is properly cited.

\begin{abstract}
This study assessed the management practices for controlling porcine cysticercosis (PC) on pig farms and in pork at the slaughter slabs in two counties (Busia and Kakamega) of Western Kenya. A total of 162 pig-rearing households at the farm level, 26 butcher owners, and 26 slaughter slab workers at the slaughter slab level were interviewed using a structured questionnaire. Data were analyzed using the "Statistical Analysis System" (SAS) programme. Results indicated that the frequent management practices used at the farm level $(p<0.05)$ were rearing pigs under free range $(69.1 \%)$, latrine ownership by households $(87.7 \%)$, and use of pit latrines $(72.8 \%)$ in households. At the slaughter level $(p<0.05)$, results of the butcher owners $(76.9 \%)$ and slaughter slab workers $(62.5 \%)$ revealed that meat inspection was not practiced adequately in the two areas of study. The results imply that slaughtered pigs for human consumption were not adequately inspected, and thus, the study recommends for implementation of effective pig management practices at the farm level and pork meat inspection at slaughter slabs to prevent PC infections and assure food safety along the pork value chain.
\end{abstract}

\section{Introduction}

Porcine cysticercosis (PC) is an infection of pigs which is prevalent in many developing countries [1] with high effect on public health and agriculture [2,3]. The disease is caused by Taenia solium which also causes cysticercosis in pigs, seizures and death in pigs $[4,5]$, and epilepsy in humans $[6,7]$. The zoonotic tapeworm T. solium has a two-host life cycle: the indirect one in humans as the definitive host harboring the mature tapeworm in the small intestine, causing taeniasis and the second with pigs as a normal intermediate host harboring the larval Cysticerci which encyst in the muscles and brain and cause porcine cysticercosis [8]. Transmission of T. solium is related to socioeconomic, behavioural, and environmental factors $[9,10]$. This was confirmed in a study in Western Kenya [11] which reported that inadequacy in meat inspection, sanitation, and cooking habits were contributing factors to cysticercosis transmission for Taenia spp. Contact with infected human faecal waste by pigs is a requisite for the successful propagation of the parasite's lifecycle [12].

In pig farming, external and internal biosecurity measures are critical tools in preventing the transmission of diseases, contributing to public health and improving livelihood of pig farmers [13]. Biosecurity encompasses bioexclusion, biocontainment, and biomanagement. The three practices are distinct but often blended with sets of actions and overlapping components. Most often, pig 
producers focus on bioexclusion and biomanagement while neglecting biocontainment which is the prevention of the spread of disease agents to neighbors or even long-distance transfer. In bioexclusion, the external biosecurity involves preventing the introduction of new pathogens/diseases within a pig unit from outside source, while biomanagement refers to the combined effort to control economically important infectious diseases that are already present in the farm population [14].

The observation of routine farm biosecurity constitutes a priority solution in the minimization of risk in disease spread [15]. It has been documented that total confinement of pigs poses welfare issues and could create other management problems such as aggressiveness and biting [16-18]. The feasibility of the intensification of livestock production requires long-term application of the One Health approach [19], focusing on the mitigation of the health risks at the interfaces between animals and humans in different ecosystems [20]. Studies elsewhere have reported that safe slaughter of pigs and monitoring of rejected carcasses found to be infected at the farm level contributed to the interruption of the parasite life cycle [21]. Poor implementation of biosecurity measures exposes pigs to the risk of PC disease $[18,22]$. Estimating the extent of the risks of $\mathrm{PC}$ and its consequences to pig farming requires well-maintained and updated pig production and management records. However, the veterinary reports, farm records, and other important statistics on pig farming are usually absent, inaccurate, or completely missing in various households and slaughter slabs. This study was undertaken to determine the management practices frequently used by pig-rearing farmers and the level of implementation of meat inspection at various slaughter slabs in Busia and Kakamega counties of Western Kenya.

\section{Materials and Methods}

2.1. Study Site and Questionnaire. This study was conducted from August to September 2018 within 9 villages within Busia and Kakamega Counties (Figure 1), two of the fortyseven (47) Counties of Kenya situated in the Western Kenya. The Western Region is located in the Western part of Kenya and borders of Uganda. It covers an area of $8,361 \mathrm{~km} 2$ $(2,867.3$ sq miles) and an estimated population of $5,021,843$ (Census 2019) and population density of 590/km2 (1,500/sq $\mathrm{mi})$. The climate is mainly tropical, with variations by County due to altitude. The whole region experiences heaviest rainfall in April and lowest in January, with the long rains which is at its peak between late March and late May. The minimum temperatures range from $14^{\circ} \mathrm{C}$ to $18^{\circ} \mathrm{C}$ and maximum of $30^{\circ} \mathrm{C}$ to $36^{\circ} \mathrm{C}$ throughout the year (24). The villages have high concentration of free scavenging pigs within Busia (Mundika, Bugengi, Nango'ma, Lwanya, Murende) and Kakamega Counties (Shikulu, Shivagala and Lunenele for Idako central), Mukongolo for Idakho North). The human population at risk of taeniasis of Busia and Kakamega is 893,681 and $1,867,579$, respectively [23].

Qualitative data on management practices influencing the disease were collected through interview using structured questionnaires which were translated in the national language and local language for some respondents during the interview. A structured questionnaire on pig farming management practices at the farm level was administered to 162 pig-rearing smallholder households, on the prevailing management practices. The pig-rearing smallholders were composed by 102 (63.75\%) from Busia and 60 (36.25\%) from Kakamega, respectively. A separate questionnaire on meat inspection implementation at the slaughter slab level was administered to 26 licensed butcher owners who brought their pigs at the slaughter slabs during the period of the data collection and 26 slaughter slab workers to collect information on the level of implementation of meat inspection. All slaughter slabs (Khayega, Shinyalu, and Malinya from Kakamega county; Musambaruwa and Matayos from Busia county) in the selected clusters were sampled. Variables defining management practices and meat inspection implementation were collected using the binary response [24] from farmers and slaughter slabs. Respondents would indicate whether they had frequently (yes) or had not frequently practiced (no) against a set of nine measures of management practices, namely, free-range pig keeping, use of outdoor defecation by humans, presence of latrine by the household, using of pit latrines by the household, sourcing water outside the farm, sourcing feed outside the farm, routine deworming, routine vaccination, presence of a fenced farm, and meat inspection (Table 1).

2.2. Data Analysis. Qualitative data on management practices from pig-rearing households, butcher owners who approached at the slaughter slabs. and slaughter slab workers were entered into Microsoft Excel (2007) and exported to SAS version 9.1.3 [24] for analysis. Descriptive statistics were used to summarize respondents' demographic characteristics and management practices [26].

\section{Results}

3.1. Demographic Characteristics of Farmers and Butcher Owners by Counties. A total of 214 respondents comprising 162 pig-rearing households, 26 butcher owners, and 26 slaughter slab workers were interviewed at the farm and slaughter slab points in Busia and Kakamega counties of Western Kenya. Out of the 162 pig-rearing households interviewed, majority, $37.7 \%, 26.5 \%$, and $10.5 \%$ were youthful farmers whose age groups varied between 21 and 30,31 and 40, and 11 and20, respectively. One-quarter (25.5\%) of the households interviewed were over $41-50$ years old, and $53.1 \%$ belonged to the female gender, while $41.7 \%$ had no formal school education. A majority (77.2\%) of farmers in Busia and Kakamega counties had kept pigs for a period of 6-10 years, while $22.8 \%$ had kept them for an average period of 28-35 years (Table 2).

For butcher owners, out of the 26 respondents interviewed, majority, 53.9\% were between 11 and 20 years old, $92.3 \%$ of them were male gender, and $57.7 \% \%$ had secondary school education. A majority (46.2\%) of butcher 


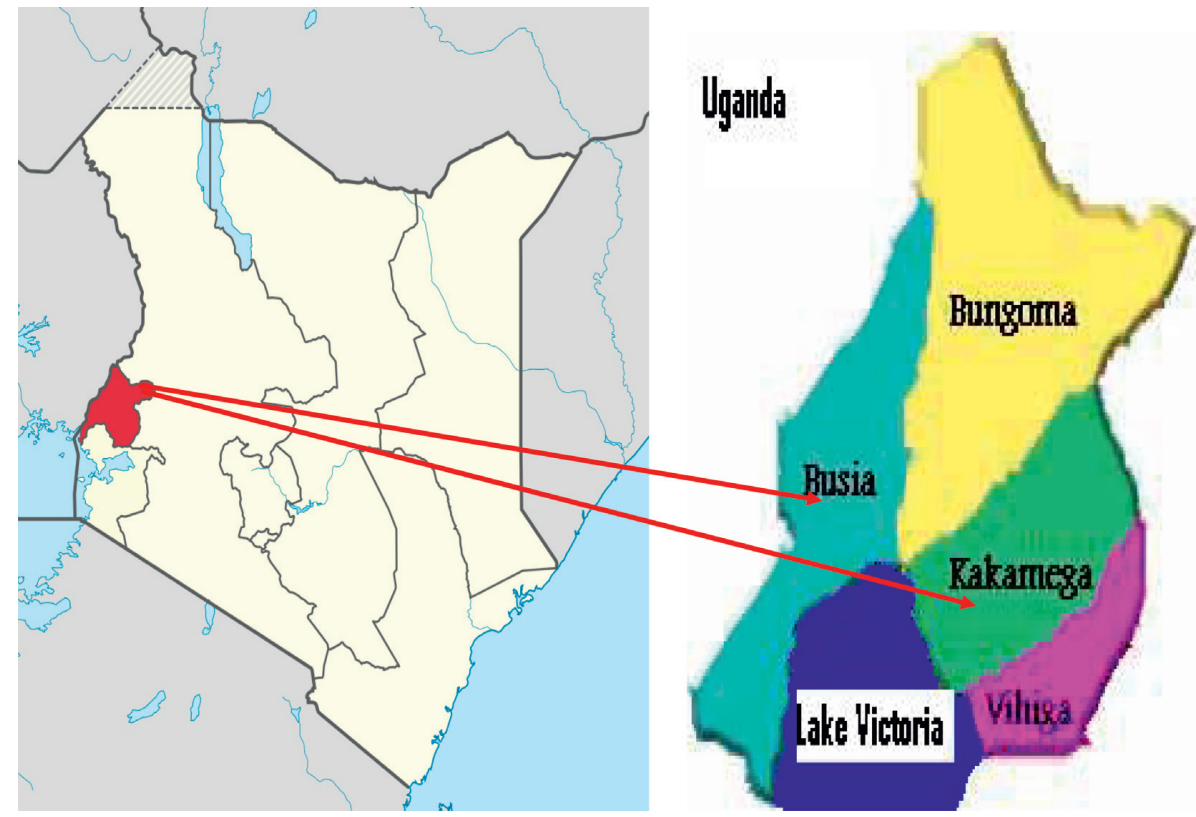

Figure 1: Map of Kenya showing Western Kenya (red color). The red arrows show Busia and Kakamega counties. Source: Kenya National Bureau of Statistics, 2019.

TABLE 1: Management practices, type of questions, and responses.

\begin{tabular}{lcc}
\hline Management practices & Type of questions & Responses \\
\hline $\begin{array}{l}\text { Free-range pig keeping } \\
\text { Use of outdoor defecation }\end{array}$ & Are your pigs kept outdoors? & Yes/no \\
$\begin{array}{l}\text { Presence of latrine at the household } \\
\text { Use of pit latrine by the household }\end{array}$ & Are outdoor bushes used for defecation? & Yes/no \\
$\begin{array}{l}\text { Sourcing water outside the farm } \\
\text { Sourcing feed outside the farm }\end{array}$ & Does the household own a pit latrine? & Yes/no \\
$\begin{array}{l}\text { Routine deworming } \\
\text { Routine vaccination }\end{array}$ & Whether farmers sourcing water outside the farm or not? & Yes/no \\
$\begin{array}{l}\text { Presence of a fenced farm } \\
\text { Meat inspection }\end{array}$ & Whether farmers sourcing feed outside the farm or not? & Yes/no \\
\hline
\end{tabular}

TABLE 2: Farmers' demographic characteristics $(n=162)$.

\begin{tabular}{|c|c|c|c|}
\hline Variables & Statement & Frequency & Percent \\
\hline \multirow{4}{*}{ Age (years) } & $11-20$ & 41 & 25.3 \\
\hline & $21-30$ & 61 & 37.7 \\
\hline & $31-40$ & 43 & 25.5 \\
\hline & $41-50$ & 17 & 10.5 \\
\hline \multirow{3}{*}{ Gender } & Male & 76 & 46.9 \\
\hline & Female & 86 & 53.1 \\
\hline & None & 67 & 41.4 \\
\hline \multirow{3}{*}{ Education level } & Primary & 41 & 25.3 \\
\hline & Secondary & 46 & 28.4 \\
\hline & College/university & 8 & 4.9 \\
\hline \multirow{3}{*}{ Farmer occupation } & Farming & 153 & 94.4 \\
\hline & Public employee & 4 & 2.5 \\
\hline & Private employee & 5 & 3.1 \\
\hline \multirow{5}{*}{ Farmers' pig production experience (years) } & 10-Jan & 125 & 77.2 \\
\hline & 20-Nov & 31 & 19.1 \\
\hline & $21-30$ & 4 & 2.5 \\
\hline & $31-40$ & 1 & 0.6 \\
\hline & $41-50$ & 1 & 0.6 \\
\hline
\end{tabular}


TABLE 3: Management practices implemented at the farm level within Busia and Kakamega counties $(n=162)$.

\begin{tabular}{|c|c|c|c|c|c|}
\hline Management practices & Practice & Count & Percent & OR & $p$ value \\
\hline \multirow{2}{*}{ Free-range pig keeping } & Frequently & 112 & 69.1 & 2.24 & $<0.0001$ \\
\hline & Not frequently & 50 & 30.9 & & \\
\hline \multirow{2}{*}{ Use of outdoor defecation by humans } & Frequently & 54 & 33.3 & 0.50 & $<0.0001$ \\
\hline & Not frequently & 108 & 66.7 & & \\
\hline \multirow{2}{*}{ Presence of latrine at the household } & Frequently & 142 & 87.6 & 7.10 & $<0.0001$ \\
\hline & Not frequently & 20 & 12.4 & & \\
\hline \multirow{2}{*}{ Use of latrine by the household } & Frequently & 118 & 72.8 & 2.68 & $<0.0001$ \\
\hline & Not frequently & 44 & 27.2 & & \\
\hline \multirow{2}{*}{ Sourcing water outside the farm } & Frequently & 13 & 8 & 0.09 & $<0.0001$ \\
\hline & Not frequently & 149 & 92 & & \\
\hline \multirow{2}{*}{ Sourcing feed outside the farm } & Frequently & 21 & 13 & 0.15 & $<0.0001$ \\
\hline & Not frequently & 141 & 87 & & \\
\hline \multirow{2}{*}{ Routine deworming } & Frequently & 48 & 29.6 & 0.42 & $<0.0001$ \\
\hline & Not frequently & 114 & 70.4 & & \\
\hline \multirow{2}{*}{ Routine vaccination } & Frequently & 49 & 30.3 & 0.43 & $<0.0001$ \\
\hline & Not frequently & 113 & 69.7 & & \\
\hline \multirow{2}{*}{ Presence of a fenced farm } & Frequently & 36 & 22.2 & 0.29 & $<0.0001$ \\
\hline & Not frequently & 126 & 77.8 & & \\
\hline
\end{tabular}

owners in Busia and Kakamega counties had sold pigs for a period of 6-10 years (Table 2).

3.2. Management Practices Preventing PC Infection at the Production Level. The results (Table 3) indicate that, in the two counties (Busia and Kakamega), more farmers frequently practiced $(p<0.05)$ free-ranging pig rearing $(69.1 \%)$, have latrines $(87.6 \%)$, and used latrines $(72.8 \%)$. However, more farmers did not frequently $(p<0.05)$ practice use of outdoor defecation (66.7\%), vaccination $(69.7 \%)$, routine deworming $(70.4 \%)$, fencing the farm $(77.8 \%)$, and sourcing water $(92.0 \%)$ or sourcing feed $(87.0 \%)$ outside the farm.

3.3. Management Practice Influencing PC Infection at the Slaughter Slabs. Results from Table 4 show the attitudes of butcher owners and slaughter slab workers towards the level of implementation of meat inspection as a management practice at slaughter slabs. However, more of the butcher owners (76.9\%) and slaughter slab workers $(61.5 \%)$ attested that the meat inspection is frequently $(p<0.05)$ practiced, and 23.1 and $38.1 \%$ of them, respectively, did not attest that.

\section{Discussion}

This paper describes the pig farming management practices and meat inspection implementation at farm and slaughter slab levels to investigate factors favouring porcine cysticercosis in Busia and Kakamega counties. The demographic descriptors revealed that out of the 162 farmer population interviewed, $37.7 \%$ were aged between 21 and 30 years, $53.1 \%$ were of the female gender, $41.4 \%$ had no formal school education, and $77.2 \%$ had kept pigs for a period of 6 to 10 years (Table 2). These findings were similar to those reported that the female gender dominated rearing and owning pigs in the rural areas of Western Kenya [26, 27] and other
TABle 4: Assessment of meat inspection implementation by respondents in the two counties.

\begin{tabular}{lccccc}
\hline Respondents & $\begin{array}{c}\text { Meat } \\
\text { inspection }\end{array}$ & Frequency & Percent & OR & $\begin{array}{c}p \\
\text { value }\end{array}$ \\
\hline $\begin{array}{l}\text { Butcher } \\
\text { owners }\end{array}$ & $\begin{array}{c}\text { Frequently } \\
\text { Not }\end{array}$ & 20 & 76.9 & 3.3 & 0.006 \\
& $\begin{array}{l}\text { frequently } \\
\text { Workers }\end{array}$ & 6 & 23.1 & & \\
& $\begin{array}{c}\text { Frequently } \\
\text { Not }\end{array}$ & 16 & 61.5 & 1.6 & 0.2393 \\
& frequently & 10 & 38.5 & & \\
\hline
\end{tabular}

African countries [28-30]. The findings agree with the report by Ampaire and Totchschild [31] that, in Africa, women are traditionally empowered to rear and own pigs as opposed to cattle. These findings differed from early reports on pig farmer age ranges of $12-88$ and $45-60$ years in Homa Bay and Embu counties of Kenya [32-34]. They also reported that $86.4 \%$ and $92.6 \%$ pig farmers in Uganda and Kenya (Embu county), respectively, were males. This variation could be attributed to the sociocultural differences in the areas of this study.

Pigs in the two counties were predominantly reared under the free-range system at the farm level (69.1\%) (Table 3). The presence of latrines at households and use of structurally dilapidated, unhygienic pit latrines for human waste disposal formed the main bioexclusion, biocontainment, and biomanagement practices with a frequency of up to $87.7 \%$ and $72.8 \%$ in the surveyed farms. Studies elsewhere had established a significant positive relationship between inappropriate use of latrines and PC prevalence [33, 35]. It has been documented that keeping pigs under the free-range system elevated the risk of pigs acquiring T. solium infection that leads to the endemicity of zoonotic porcine cysticercosis [36]. Findings in this study not only concurred with this fact but also corroborated the information that pigs kept under the free-range pig production system, compounded by poor utilization or lack of latrines, could have been the main 
contributing factors for the spread and endemicity of PC in the two counties at the farm level.

In this study, 76.9 and $61.5 \%$ of butcher owners and slaughter slab workers reported that meat inspection was frequently implemented at slaughter slabs (Table 4). It was observed that meat inspection practice was occasionally ignored in some slaughter slabs in seasons of high demand and was not thoroughly performed in the sense that infected animals could be slaughtered, and uninspected meat easily found its way into the human food chain. The observations here concur with those given by Gabriël et al. [37], who reported that inadequate meat inspection was a contributory factor to the spread of the infection by Taenia solium which could lead to the emergence or re-emergence of the disease in pig farming systems. This finding suggests that inadequate meat inspection at the slaughter slabs is a critical factor influencing the spread of this disease in Busia and Kakamega counties at the slaughter slab points.

\section{Conclusions}

The free-range pig production system (no fencing and scavenging) and inappropriate use of latrines were the critical poor management practices that propagated and propelled PC infection at the farm level in Busia and Kakamega counties. The meat inspection practice as a factor of biosecurity at slaughter slabs was not adequate in the two counties of Western Kenya. These findings suggested that there is a need for implementation of effective pig biosecurity measures to prevent PC infections and ensure food safety along the pork value chain in Western Kenya. This will require collaboration with policymakers who have in their mandate the reinforcement of the regulations by inspiring farmers through sensitization training and strengthening the meat inspection in Western Kenya.

\section{Data Availability}

The data used to support the findings of this study are available from the corresponding author upon request.

\section{Conflicts of Interest}

The authors declare that they have no conflicts of interest.

\section{Acknowledgments}

The authors acknowledge the farmers, slaughter slab owners, butcher owners, slaughter slab workers, and the Directorate of Veterinary Services in Busia and Kakamega counties for their collaboration, support, and time availed to ensure the completion of this study. This work was supported by the African Centre of Excellence in Sustainable Agriculture and Agribusiness Management (CESAAM), Egerton University.

\section{References}

[1] K. E. Mwape, I. K. Phiri, N. Praet et al., "The incidence of human cysticercosis in a rural community of Eastern
Zambia," PLoS Neglected Tropical Diseases, vol. 7, no. 3, pp. 1-7, 2013.

[2] L. D. Dahourou, O. B. Gbati, A. Millogo, A. Dicko, C. R. Roamba, and L. J. Pangui, "Analysis of the knowledge, attitudes and practices of populations in four villages of the Boucle du Mouhoun Region (Burkina Faso) Regarding Tænia solium Life Cycle," Health, vol. 10, no. 1, pp. 95-106, 2018.

[3] L. F. Thomas, L. J. S. Harrison, P. Toye et al., "Prevalence of Taenia solium cysticercosis in pigs entering the food chain in western Kenya," Tropical Animal Health and Production, vol. 48, no. 1, pp. 233-238, 2016.

[4] M. Donadeu, M. W. Lightowlers, A. S. Fahrion, J. Kessels, and B. Abela-Ridder, "Taenia solium: WHO endemicity map update," Releve Epidemiologique Hebdomadaire, vol. 91, no. 49-50, pp. 595-599, 2016.

[5] I. Gonzales, J. T. Rivera, and H. H. Garcia, "Pathogenesis ofTaenia soliumtaeniasis and cysticercosis," Parasite Immunology, vol. 38, no. 3, pp. 136-146, 2016.

[6] H. H. Garcia, T. E. Nash, and O. H. Del Brutto, "Clinical symptoms, diagnosis, and treatment of neurocysticercosis," The Lancet Neurology, vol. 13, no. 12, pp. 1202-1215, 2014.

[7] T. E. Nash and H. H. Garcia, "Diagnosis and treatment of neurocysticercosis," Nature Reviews Neurology, vol. 7, no. 10, pp. 584-594, 2011.

[8] M. Donadeu, A. S. Fahrion, P. L. Olliaro, and B. Abela-Ridder, "Target product profiles for the diagnosis of Taenia solium taeniasis, neurocysticercosis and porcine cysticercosis," PLoS Neglected Tropical Diseases, vol. 11, no. 9, Article ID e0005875, 2017.

[9] J. Kylie, M. Brash, A. Whiteman et al., "Biosecurity practices and causes of enteritis on Ontario meat rabbit farms," $\mathrm{Ca}$ nadian Veterinary Journal, vol. 58, no. 6, pp. 571-578, 2017.

[10] N. A. Wardrop, L. F. Thomas, P. M. Atkinson et al., "The influence of socio-economic, behavioural and environmental factors on Taenia spp. transmission in Western Kenya: evidence from a cross-sectional survey in humans and pigs," PLoS Neglected Tropical Diseases, vol. 9, no. 12, 2015.

[11] V. Dermauw, P. Dorny, U. C. Braae et al., "Epidemiology of Taenia saginata taeniosis/cysticercosis: a systematic review of the distribution in southern and eastern Africa," Parasites \& Vectors, vol. 11, no. 1, p. 578, 2018.

[12] H. A. Ngowi, S. Mukaratirwa, F. P. Lekule et al., "Agricultural impact of porcine cyisticercosis in Africa: a revieuw," in Novel Aspects on Cysticercosis and Neurocysticercosis, vol. 4, pp. 76-92, IntechOpen, London, UK, 2013.

[13] M. Laanen, D. Persoons, S. Ribbens et al., "Relationship between biosecurity and production/antimicrobial treatment characteristics in pig herds," The Veterinary Journal, vol. 198, no. 2, pp. 508-512, 2013.

[14] D. G. Levis and R. B. Baker, Biosecurity of Pigs and Farm Security, University of Nebraska Press, Lincoln, NE, USA, 2011.

[15] FAO/OIE/World Bank (Food and Agriculture Organization of the United Nations/World Organisation for Animal Health/World bank), Good Practices for Biosecurity in the Pig Sector, vol. 169, pp. 1-92, FAO Animal Production and Health Paper, Rome, Italy, 2010.

[16] S. Bellini, D. Rutili, and V. Guberti, "Preventive measures aimed at minimizing the risk of African swine fever virus spread in pig farming systems," Acta Veterinaria Scandinavica, vol. 58, no. 1, pp. 1-10, 2016.

[17] E. Lara de la Casa, "La cría intensiva de cerdos: consideraciones éticas," Derecho Animal. Forum of Animal Law Studies, vol. 8, no. 3, pp. 1-8, 2017. 
[18] J. M. Mbuthia, T. O. Rewe, and A. K. Kahi, "Evaluation of pig production practices, constraints and opportunities for improvement in smallholder production systems in Kenya," Tropical Animal Health and Production, vol. 47, no. 2, pp. 369-376, 2015.

[19] J. A. K. Mazet, D. L. Clifford, P. B. Coppolillo, A. B. Deolalikar, J. D. Erickson, and R. R. Kazwala, "A "one health" approach to address emerging zoonoses: the HALI project in Tanzania," PLoS Medicine, vol. 6, no. 12, pp. 1-5, 2009.

[20] D. Nabarro and C. Wannous, "The potential contribution of livestock to food and nutrition security: the application of the One Health approach in livestock policy and practice," Revue Scientifique et Technique de l'OIE, vol. 33, no. 2, pp. 475-485, 2014.

[21] S. M. Shonyela, E. M. Mkupasi, S. C. Sikalizyo, E. M. Kabemba, H. A. Ngowi, and I. Phiri, "An epidemiological survey of porcine cysticercosis in Nyasa District, Ruvuma Region, Tanzania," Parasite Epidemiology and Control, vol. 2, no. 4, pp. 35-41, 2017.

[22] E. Assana, F. Amadou, E. Thys et al., "Pig-farming systems and porcine cysticercosis in the North of Cameroon," Journal of Helminthology, vol. 84, no. 4, pp. 441-446, 2010.

[23] Kenya National Bureau of Statistics (KNBS), Kenya Population and Housing Census: Volume I. Population by County and Sub-County, 2019.

[24] SAS Institute Inc., Base $S A{ }^{\circledR}$ 9.1.3 Procedures Guide, SAS Institute Inc., Cary, NC, USA, Second edition, 2006.

[25] G. James, D. Witten, T. Hastie, and R. Tibshirani, "An introduction to statistical learning: with applications in R," Springer Texts in Statistics, Vol. 103, Springer Science+Business Media, New York, NY, USA, 2013.

[26] J. M. Kagira, P. W. N. Kanyari, N. Maingi, S. M. Githigia, J. C. Ng'ang'a, and J. W. Karuga, "Characteristics of the smallholder free-range pig production system in western Kenya," Tropical Animal Health and Production, vol. 42, no. 5, pp. 865-873, 2010.

[27] F. Mutua, S. Arimi, W. Ogara, C. Dewey, and E. Schelling, "Farmer perceptions on indigenous pig farming in Kakamega District, Western Kenya," Nordic Journal of African Studies, vol. 19, no. 1, pp. 43-57, 2010a.

[28] K. Ikwap, M. Jacobson, N. Lundeheim et al., "Characterization of pig production in Gulu and Soroti districts in northern and eastern Uganda," Livestock Research for Rural Development, vol. 26, no. 4, 2014.

[29] E. D. Karimuribo, S. W. Chenyambuga, V. W. Makene, and S. Mathias, "Characteristics and production constraints of rural-based small-scale pig farming in Iringa region, Tanzania," Livestock Research for Rural Development, vol. 23, no. 8, 2011.

[30] T. G. Sibongiseni, J. W. Oguttu, and M. M. Masafu, "Pig farming in rural South Africa: a case study of uThukelaDistrict in KwaZulu-Natal," Indian Journal of Animal Research, vol. 50, no. 4, pp. 614-620, 2016.

[31] A. Ampaire and M. F. Totchschild, "Pigs, goats and chickens for rural development: small holder farmer's experience in Uganda," Livestock Research for Rural Development, vol. 22, no. 6, p. 1, 2010.

[32] CARE International Kenya, Community-Adaptation-ActionPlans-in-Embu County-Kenya. Findings on Vulnerability to Climate Change and Community Adaptation Action Planning in Iria-Itune, Kamarandi, Mutwabare and Ntharawe Communities, Mbeere North and South, Embu, Kenya 2015-2016, Care International Kenya, Nairobi, Kenya, 2017.
[33] E. E. Eshitera, S. M. Githigia, P. Kitala et al., "Prevalence of porcine cysticercosis and associated risk factors in homa Bay District, Kenya," BMC Journal of Veterinary Research, vol. 5, no. 8, pp. 234-240, 2012.

[34] R. K. Kithinji, T. I. Kanui, J. N. A. Ndathi, and R. M. Mwobobia, "Characterization of pig production systems in EMBU West Sub County, EMBU County, Kenya," International Journal of Advanced Research, vol. 5, no. 6, pp. 1527-1533, 2017.

[35] C. S. Sikasunge, I. K. Phiri, A. M. Phiri, P. Dorny, S. Siziya, and A. L. Willingham, "Risk factors associated with porcine cysticercosis in selected districts of Eastern and Southern provinces of Zambia," Veterinary Parasitology, vol. 143, no. 1, pp. 59-66, 2007.

[36] World Health Organization, "Investing to overcome the global impact of neglected tropical diseases," Third WHO Report on Neglected Tropical Diseases. WHO/HTM/NTD/ 2015.1, World Health Organization, Geneva, Switzerland, 2015.

[37] S. Gabriël, M. V. Johansen, E. Pozio et al., "Human migration and pig/pork import in the European Union: what are the implications for Taenia solium infections?" Veterinary Parasitology, vol. 213, no. 1-2, pp. 38-45, 2015. 